\title{
Indicators for Public Sector Innovations: Theoretical Frameworks and Practical Applications
}

\author{
Rainer Kattel, Aleksandrs Cepilovs, Veiko Lember and Piret Tõmurist
}

\begin{abstract}
The paper maps and analyzes all existing practical exercises aiming to develop indicators for public sector innovations. To our knowledge this is the first attempt to comprehensively gather information about various international efforts. We only considered such exercises where actual indicators were developed and used at least once. We map five such exercises through extensive desk research and 13 interviews with surveyed project members. The paper shows that all existing attempts to measure public sector innovations operate within a rather limited conception of the public sector (efficiency), neglecting other possible logics (e.g. legitimacy); the existing exercises also neglect large areas of public sector activities, e.g. cooperation with business and third sectors (such as service co-creation, public-private partnership practices). This narrow focus often dictates that indicators and their technical assumptions are copied from the private sector; none of the five analyzed exercises utilized public administration experience and research (e.g. on performance measurement). The paper argues that instead of trying to come up with quantified indicators, public sector innovations should be assessed in complex evaluation frameworks.
\end{abstract}

\section{Introduction}

As innovations in the public sector become more important both in public sector reform and academic discussions, so do the attempts to measure these innovations and their effects. However, as with other public sector phenomena, the measurement attempts for public sector innovations are riddled with difficulties, both conceptual (what to measure) and technical (how to measure). Innovations, whether those appear in the public or in the private sector, are directly related to the performance of the organizations that introduce them. Hence, we look not only at the measurement of innovation activities and innovations as such, but also their effects.

In this paper we look at existing practical attempts (projects) to develop indicators for public sector innovations. The aim of the paper is to map these exercises, 
their backgrounds, technicalities and eventual successes or failures. To our knowledge this is the first attempt to comprehensively gather information about various international efforts. We only considered such exercises where actual indicators were developed and used at least once. We map five such exercises through extensive desk research and 13 interviews with surveyed project members.

The paper is structured as follows. Based on existing literature on public sector innovations and performance measurement, we first draw up a theoretical matrix of how such innovations could be potentially measured; we propose a set of hypotheses. We propose that public sector innovations can be conceptualized to operate within a matrix of two different logics: the logic of efficiency and the logic of legitimacy; and these logics can be used to either measure innovations within the public sector or innovations through the public sector. Then, second, we describe five actual projects to create indicators for public sector innovations. Third, based on interviews with teams behind these projects, we discuss how these attempts have fared, and what their strengths and weaknesses are. Our conclusion is that all existing attempts to measure public sector innovations operate within the logic of efficiency, neglecting the logic of legitimacy; the existing projects also neglect large areas of public sector activities of cooperation with business and third sectors (e.g. co-creation, public-private partnership practices). Further, we show that the logic of efficiency often dictates that indicators and their technical assumptions are copied from the private sector. We end by showing how public sector innovations could be measured, or at least utilized, in the public sector, from the perspective of legitimacy. We argue that instead of trying to come up with quantified indicators, public sector innovations should be assessed in complex evaluation frameworks.

\section{Public sector innovations: what do we attempt to measure?}

The first difficult yet obvious question in the context of measuring public sector innovations is what in fact constitutes a public sector innovation (as opposed to simply changes taking place in public sector organizations; see also Lynn 1997, 98). If we were to know how to differentiate innovations from non-innovations in the public sector then a second question would arise: while private sector activities are often measured through various performance management systems, from selfevaluation tools to R\&D inputs and outputs to productivity measurements, can these also be used in the case of public sector innovation?

Answering these two questions should give us a landscape within which all theoretically possible and practically experimented measurements of public sector innovations would take place. We attempt to answer these questions by a highly concise summary of existing literature.

\subsection{Public sector innovations: what does the literature say?}

It turns out that previous literature on public sector innovation says a whole lot of different things about what public sector innovations are. Trying to conceptualize 
public sector innovations in fact has a long history, and we can divide these debates into four historical and also conceptually different periods. ${ }^{1}$

\section{The Weberian period;}

\section{The Schumpeterian period;}

3. The organizational theory period;

4. The autochthonous theory period.

In fact the Weberian period starts way before Max Weber was even born, namely with Alexis de Tocqueville. These two were engaged in what might be called a rather well hidden debate about public sector innovations (Kattel et al. 2013). Tocqueville's analysis, and admiration, of state level administration is famous, Weber's counterarguments are much more scattered and less well known. ${ }^{2}$ Tocqueville's main question in looking at the US state and especially township-level administration was: how can diverse townships in New England, without central administration, still provide relatively uniform public services, especially under an administrative system where most public functions are fulfilled by elected officials (Tocqueville 1876, 92)? He explained this with judicial oversight of administrations, and called both - decentralized administration and judicial oversight - innovations (ibid.) In Tocqueville's view, decentralized administration with elected officials and judicial oversight works better than centralized administrations (which, he argues, was an innovation of the French revolution; ibid., 121): centralized administrations have more resources, are good at regulating business, maintaining social order and security but also keep society equally from improvement and decline (ibid., 113); centralized administrations are good at mastering resources to combat problems but they are poor at rejuvenating what might be called socio-political resources for change (ibid., 109). When we jump two-thirds of a century further, we can see that all the ills of centralized administration described by Tocqueville become positives in Weber's view: in order to keep social order, that is to retain authority and keep society functioning, centralized bureaucracy is the "technically" better instrument over elected officials (Weber 2002, 156; further also 545-550 and 561). Elected officials and other "schöpferische' Betätigung der Beamten" lead rather to unpredictability and to bureaucracy that seeks to retain its own power, in other words to rent-seeking behavior (565). In effect, Tocqueville and Weber talk about, first, enablers and constraints within the public sector, and denote changes to enablers and constraints as innovations (innovations such as the centralization of administrations can constrain local participation in political processes and yet at the same time enable more equitable service delivery). Essentially, for the Weberian period, public sector innovations are such changes in the public sector that realign enablers and constraints and in one way or another influence the authority and legitimacy of the

${ }^{1}$ A more detailed discussion of these periods can be found in Kattel et al. (2013).

2 Tocqueville's were published in 1835 and 1840; Weber remarks can be found in Wirtschaft und Gesellschaft from 1922. 
given public sector actor. This dimension of authority and legitimacy is almost completely missing in all subsequent debates. ${ }^{3}$

The Schumpeterian period is characterized by Schumpeter's theory of innovation, which in fact is an application in economics and business of his wider theory of how evolutionary change takes place in societies. Alas, Schumpeter never really developed his wider theory of social change (see also Andersen 2009). In his 1939 Business Cycles, Schumpeter states, in a footnote, that he "believes, although I cannot stay to show, that theory [of innovation] here expounded is but a special case, adapted to the economic sphere, of a much larger theory which applies to change in all spheres of social life, science and art included" (1939, 97). His 1912 Theorie der wirtschaftlichen Entwicklung / The Theory of Economic Development ${ }^{4}$ apparently assumes a similar theory, without going into greater detail, either. We can deduce that what Schumpeter meant by this larger theory of change in social life is that change is driven by entrepreneurial, creative persons, or "new men", as he called them in 1939, that look for "new combinations", that is innovative solutions, and thus bring forth evolutionary changes, entirely new ways of doing things (in business, politics, art, science, etc.) that will spread, in some cases more than others, throughout the given sphere of life. Some of these changes will change value systems and disrupt incumbent hierarchies. In the economic sphere, such individuals drive innovations and, thus, economic growth. The role of the public sector in entrepreneurial innovation is twofold: first, the public sector can take on the role of the entrepreneur (in fact, Schumpeter argues that in socialism, as there is no private ownership, the state will be the sole innovator; 1912, 173); second, innovations in businesses can also be “called forth" by governments $(1939,84)$.

In sum, what we can take from Schumpeter is that since early theories of innovation, the public sector has had a dual character vis-à-vis innovation: it itself can be changed by innovators, and the state can play a crucial role for business innovations, as well (either by directly leading or indirectly supporting entrepreneurial activity). This foreshadows rather closely the currently emerging conceptual dichotomy between innovations in the public sector and innovations through the public sector (European Commission 2013; EU Expert Group on Public Sector Innovation 2013).

The organizational theory period. Research explicitly dealing with innovation in the public sector goes back at least to the 1960s; however, its inception seems somewhat accidental in nature. Researchers in organizational theory dealing with innovation and how the organizational structure supports creative work and novel ideas often did not differentiate between public and private-sector organizations (this nondifferentiation goes, in fact, back to Taylor's Principles of Scientific Management as well as to Weber's bureaucracy as an ideal type for both public and private organizations). For instance, Thompson talks explicitly about business and government orga-

3 It can be argued that a recently emerging literature on social innovation (see Voorberg et al. 2015 for an overview) tries to fill this gap in public sector innovation literature by looking at values and social relevance and thus moves the discussions towards issues of authority, trust, etc.

4 We use here the original first German edition, as in later editions (that served as the basis for the English translation as well) these discussions were cut by Schumpeter; so, e.g., the second chapter of the original edition runs to almost 100 pages, the English translation carries only half as many. In this chapter, Schumpeter discusses his theory of innovation. 
nizations and their "capacity to innovate" $(1965,1)$ and defines innovation as the "generation, acceptance, and implementation of new ideas, processes, products or services. Innovation therefore implies the capacity to change or adapt" (1965, 2; see also, e.g., Mohr 1969). Much of the subsequent management and organization theory literature dealing with innovation moves effortlessly from the private to the public sector and back, and deals in fact mostly with the paradox of managers calling for innovative ideas that end up meeting resistance in implementation often from the same managers or organizational structures (Lynn 1997). This strand of research dealt mostly with the diversity of tasks and incentives in an organization (Becker and Whisler 1967 is a good overview). One of the key figures in this tradition is James Q. Wilson, whose definition of (public sector) organizational innovation remained largely the same from the 1960s to the 1980s: "real innovations are those that alter core tasks; most changes add to or alter peripheral tasks" $(1989,225)$. Wilson, without referring to Schumpeter, understood these alternations in core tasks to be evolutionary in nature and in impact: "Government agencies change all the time, but the most common changes are add-ons; a new program is added on to existing tasks without changing the core tasks or altering the organizational culture" (ibid.).

Thus, there is a rather extensive literature that emerged from organizational theory that incidentally or purposefully deals with public sector innovation and where the latter is defined more or less similarly from the 1960s to the 1990s. This literature uses a more or less varied Schumpeterian notion of innovation, but it almost does not differentiate at all between private and public sectors, and thus innovations in any organization can be defined as significant and enduring changes in core tasks. This way innovation should be different from incremental changes in organizations (public or private) and in fact is similar to (technological) breakthroughs familiar from the private sector evolutionary literature (see, e.g., Lynn 1997, who explicitly uses the concept of breakthrough).

The autochthonous theory period. In the 2000s, literature dealing with public sector innovation tried to move away both from private sector Schumpeterian approaches emphasizing novelty in action and from organizational-level changes towards innovation genuinely attributable to the public sector and towards discussing innovations in public services and governance (see, e.g., Hartley 2005; Moore and Hartley 2008; also Verhoest et al. 2006; Pollitt 2011; Osborne and Brown 2005, 2013). Some of this literature is derivative from service innovation literature, which tried to address the specificities of innovation in service industries. This literature itself developed through several stages: from focusing on technology adoption as a driver for innovation in services towards the endogenization of innovation in services (both private and public) (Djellal et al. 2013; also Gallouj and Zanfei 2013; also Fuglsang 2010). However, while there is a distinct attempt to discuss public sector phenomena (i.e. the decentralization of agencies or regions) and move away from the private-sector categorization and concepts (such as product, service and other types of innovations; concepts of life cycles and trajectories), there is hardly any substantial change in terms of conceptually differentiating public sector innovations from the private sector ones. The main tenets are still changes that are new to the organization and that are large and durable enough (e.g. Hartley 2005, 27; Moore and Hartley 2008, 5), or represent discontinuous change (Osborne and Brown 2005, 
2013). Hartley, for instance, delivers a useful discussion of the difference between public sector innovations in traditional, new public management and network-based paradigms of public administration (2005, 28-30). Yet, her conceptual framework is hardly different from Wilson's. Similarly to organizational theory literature, also the most recent literature on public sector innovation in the end sees innovations in the public sector as something different from incremental improvements, and that can also fail and not lead to a better public service. ${ }^{5}$ Thus, e-voting would constitute for most public sector researchers a real innovation and yet some would argue that this innovation did not really bring any improvement, or at least that the jury is still out. However, in most cases the line between innovation or not, improvement or not, is not only tenuous at best, often it seems plain arbitrary. Moore and Hartley (2008), for instance, use contracting out and private public partnerships for public sector innovation as examples; in other words, public sector innovation is another term for NPM-style reform practices. ${ }^{6}$ Thus, what is and what is not an innovation seems rather arbitrary or subjective, and this is further complicated by the fact that most attempts at measuring public sector innovations use surveys (as we will show below) - in essence further cementing subjectivity into the discussion.

Summarizing 150 years of discussion, as sketched above, on conceptualizing public sector innovations and innovations generally, we can draw the following conclusions:

\section{From the oldest literature discussing public sector innovations (Tocqueville, Weber):}

- Public sector innovations are in the most abstract sense related to public authority;

- Innovations lead to evolutionary changes in constraints and enablers that are intrinsic to the public sector (rules, relationships, institutions);

\section{From more recent public sector innovation literature:}

- These evolutionary processes use different modalities (innovations within and through the public sector), agency (the public sector proactively initiates changes or reacts to technological, environmental, etc., changes), and morphology (from incremental to discontinuous changes);

- Current literature on public sector innovations rarely deals with authority (and related phenomena, such as legitimacy, trust, etc.,) but rather with relatively specific features of these changes, e.g. with specific modalities (within public sector organizations), agency (reactions to external stimuli such as technology, politics, social challenges) and morphology (incremental changes); most of these changes are in fact not evolutionary, or their impact remains difficult to discern.

\footnotetext{
5 See, however, Fuglsang 2010.

6 See Drechsler 2005 on the role academic and policy talk fashion plays in such re-labelling practices.
} 


\subsection{Public sector performance measurement: what can we learn for measuring innovations?}

While measuring public sector innovation is still in its infancy, there is a veritable tradition of measurement in the public sector that we can look to for inspiration, namely performance measurement. Many different things can be measured in terms of services provided by the government ranging from inputs/resources, throughputs/ processes, outputs and outcomes/impacts (see, e.g., Packard 2010; Kuhlmann 2010; Sillanpää 2013). This has also led to the proliferation of performance indicators, which does not necessarily mean that the quality of indicators themselves has improved (Lonti and Gregory 2007; Drechsler 2019 on indicators, and Kattel et al. 2018 on the wider discussion of evaluation in the public sector). The goals of this process are usually tied to ideas of advancing transparency, learning, appraising, sanctioning and also showing accountability in the public sector. Simply put, the argument for measurement is based on the assumption that "what gets measured, gets done" (Osborne and Gaebler 1992). Effectiveness in the public sector is seen in theory as value creation to the citizen, which, however, has no real maximum and, thus, is very hard to quantify (Tangen 2005). Various measurement systems have been suggested to the public sector from balanced scorecards to quality management models to deal with measurement (Hasan and Kerr 2003; Sahay 2005). However, many challenges in using indicators as performance management tools have been brought out over the last decades, and while the critiques are cyclically repeated and sometimes advanced (e.g. Ridgway 1956; Smith 1995; van Thiel and Leeuw 2002; Miller 2003; Pidd 2008), very few solutions have been brought out to tackle these challenges. The main challenges of measurement in the public sector, not only technical but also conceptual ones, can be summarized as follows:

1. The diverse nature of public sector services, the wide range of users and the difficulties in defining targets (Arnaboldi and Azzone 2010). Targets do not adhere to singular profit imperatives in the public sector (Van Thiel and Leeuw 2002). When multidimensional impacts - tangible and intangible, financial and value-based, individual and system level - are concerned, prospects on how to measure these effects are largely missing in academic literature.

2. Many economic impact-evaluation methods are almost impossible to use in the public sector simply because they require effects (also intangible ones, e.g. improved health, quality of life, etc.) to be monetized. As such, measurement in the public sector is usually limited to the "product" rather than a process, "throughput". Consequently, measures are faced with the problem of "product" definition: for example, how to measure research (by scientific publication?), successful treatment (reoccurrence?) or even deterred crime. For this, tolerance of multiple definitions has been suggested as a possible solution that could capture multiple values (de Bruijn 2002).

3. At the same time, measurement in general is static, while the processes are clearly dynamic. There are time lags connected to the effects of many policies and also public sector performance. When a long-term view is taken into 
consideration, present actions can be questioned (Brax 2007). Welfare services, with a traditionally very high number of performance indicators, are found to lack measures to demonstrate the various long-term effects (Sillanpää 2013). These are problematic to measure, not only because of the unknown, but also most strategic planning cycles are 4-5 years long at most. However, in many cases, success can only be shown through long-term effectiveness that is usually only possible to describe in qualitative effects (e.g. Porter 2010).

4. As such, the application of quantitative performance measurement usually rests on proper measurement scales with decreasing ambiguity and uncertainty (see Pidd 2008). However, in this regard there are clearly situations where quantitative indicators are not the best measures. This occurs especially when practices in the public sector are in transition, complex issues are faced and when standards in place are contested (see Noordegraaf and Abma 2003). This usually leads to a value debate, for which quantitative numerical indicators are not useful (they simply represent one limited dimension of values) and the expert opinion-based approach of professional agreement is a more advanced form of evaluation.

5. Furthermore, in situations that have been described as "wicked problems" in the public sector (Rittel and Webber 1973) - i.e. innovative and sometimes conflicting processes that are not routine - conventional control systems (including static measurement) are found to make no sense, as a certain level of ambiguity and uncertainty is necessary in the processes.

The quest for measuring public sector productivity - a central concept in understanding private sector innovation dynamics on the organizational, sectoral, regional and national levels - only amplifies the conceptual and technical problems related to general public sector performance (change) indicators. Public sector productivity has many different meanings, and its significance has changed constantly over time (Andrews and Entwistle 2013, Rutgers and van der Meer 2010). It is mostly regarded today as a technical term, which refers to the ratio of outputs to inputs in producing public services (Pollitt and Bouckaert 2011, Andrews and Entwistle 2013, Rutgers and van der Meer 2010, Dunleavy and Carrera 2013). The definition of productivity is often used as a synonym to public sector technical efficiency, and in fact the terms of public sector productivity and efficiency tend to be used interchangeably in the literature (see various definitions outlined in Rutgers and van der Meer 2010, but cf. Dunleavy and Carrera 2013). At the same time, a clear distinction is usually made between productivity and related concepts. For example, while productivity (efficiency) refers to the "amount of resources used to produce a unit of output", effectiveness is mostly understood as the "the extent of goal achievement" (Etzioni 1964 in Lane 2000, 62). This, in turn, implies the need to distinguish productivity from other related concepts (in addition to effectiveness, e.g., economy, cost-effectiveness, value-for-money) when dealing with public sector performance (see also Rutgers and van der Meer 2010, Dunleavy and Carrera 2013).

At the same time, this technical approach to public sector productivity has been repeatedly challenged (see Rutgers and van der Meer 2010 for an overview), and in 
spite of the simple and eloquent definition of public sector productivity, the concept has proven to be all but unambiguous and uncontested. The simple issue that in most cases there are no markets and prices for public services means that productivity calculations would prove impossible. The central normative debate has been about the proper place of productivity among other public sector values and whether the technical approach is at all useful for the public sector. Moore's (1994) public value concept, which aims at a shift away from productivity to broader public value creation, is an example of a more recent approach reflecting the general discontent with regard to the market-loaded productivity thesis. According to the public value framework it is the citizens who should decide and express through the democratic process what kind of values are to be created by the public sector and how (O'Flynn 2007). And productivity may not even be among the parameters that the processes and outcomes of the delivery of public values are evaluated against. In short, it is the responsiveness to citizens that matters the most rather than how to structure for the efficiency that the critics insist on. This debate has some conceptual affinity to the debates about legitimacy and trust, although these remain not spelled out.

What becomes evident from the above is that although the concept of productivity seems to have occupied a highly prominent place in contemporary public policy and administration rhetoric, it has not, for various political, conceptual and analytical reasons, been extensively applied into the study and practice of public administration.

The recent developments in public productivity measurement may offer a step forward in terms of organizational productivity (e.g. Dunleavy and Carrera 2013), but the systemic perspective is still largely missing. If we look at our discussion of public sector innovations above and compare it to the productivity debate, we note a latent conflict: while productivity is best measured on organizational bases, innovations are systemic, at least on the level of a sector, that is, their impact on concrete organization may be vague and indirect and likely also with serious time lags.

Another emerging approach is experimental designs to measure performance. Experimental designs, such as randomized controlled trials (RCT), originating from medicinal drug trials, have recently gained significant traction in development economics (e.g. Banerjee and Duflo 2009; Banerjee et al. 2015) as well as in education and social science research (Torgerson and Torgerson 2008). When it comes to experimental evaluations of the effectiveness of policy interventions, RCTs are considered to be the new "gold standard". Some authors argue that RCTs are particularly suitable for the evaluation of socially complex interventions as they are able to filter the relevant data from background noise (Sheldon and Oakley 2002). Other claims in defense of RCTs and other experimental and quasi-experimental designs as reliable methodologies include: claims regarding external validity; internal validity ensured by random allocation; control and reference groups, at least in theory, are equal in terms of characteristics important to the study. The very common issue, however, when one applies RCTs beyond their initial domain of drug efficacy testing is exactly the lack of ecological validity and generalizability beyond the initial sample. A less mechanistic approach to doing RCTs based on a mixed method approach can potentially, at least to a degree, address the issue of generalizability beyond the initial sample, thus allowing it to make judgments regarding the further 
diffusion of successful innovations. The potential to use social media and related methodologies (e.g. social tagging) as experimental designs for public sector innovation measurements could be a future avenue for both practitioners and academics alike. However, currently we can only hint in this direction, there seems to be no significant research available.

\section{3 Theoretical matrix and hypothesis}

Based on the discussion of the two literature strands presented above, namely that focused on conceptualizing public sector innovation and that focused on measuring public sector performance and productivity, we can argue that the two fundamental dimensions particularly relevant to measuring or analytically capturing public sector innovations are:

1. Logic of proposed or implemented changes: This dimension has at its one extreme the logic of efficiency (or productivity), where changes deemed innovations bring more for the same or even less money; at the other extreme is the logic of legitimacy, where changes deemed innovations bring more legitimacy for public sector activities. Obviously, both extremes need to be captured analytically, and thus also measured, differently. We propose some of the most obvious ways how to measure these and suggest a rough taxonomy based on this dimension (Table 1).

Table 1. Logic of efficiency.

\begin{tabular}{|c|c|c|c|c|}
\hline Efficiency & & & & Legitimacy \\
\hline $\begin{array}{l}\text { Input/output } \\
\text { productivity }\end{array}$ & $\begin{array}{l}\text { Performance measurement } \\
\text { (outputs, outcomes etc.) }\end{array}$ & $\begin{array}{l}\text { Self-evaluation tools (e.g. } \\
\text { EFQM excellence model etc.) }\end{array}$ & $\begin{array}{l}\text { Satisfaction surveys, } \\
\text { trust surveys }\end{array}$ & $\begin{array}{l}\text { Real-time (social) } \\
\text { media watch }\end{array}$ \\
\hline
\end{tabular}

2. Impacts and feedback loops of proposed or implemented changes: Innovation in the public sector does not happen in isolation, but often engages some external parties, be those from the public, private or nonprofit sector. This dimension has at its one extreme impact/feedback from what is deemed innovation within the organization and at its other extreme impact/feedback within the private sector. Again, we can argue that both extremes need to be analyzed and measured differently, and again we can draw up a taxonomy of forms of impact/feedback that needs to be differentiated (Table 2). 
Table 2. Dimensions of public sector innovations.

\begin{tabular}{|c|c|c|c|c|}
\hline In public sector & $\leftarrow$ & & & Through public sector \\
\hline $\begin{array}{l}\text { Within a public sector } \\
\text { organization productivity }\end{array}$ & $\begin{array}{l}\text { Between public sector } \\
\text { organizations }\end{array}$ & $\begin{array}{l}\text { Public-private } \\
\text { partnerships }\end{array}$ & $\begin{array}{l}\text { Co-creation } \\
\text { practices }\end{array}$ & Private sector activities \\
\hline
\end{tabular}

These two dimensions should describe both the entirety of possible changes in the public sector that could be conceivably seen as innovations in the public sector and also describe exhaustively ways to measure or at least analytically capture such changes and their effects (Table 3).

Table 3. Analytical matrix.

\begin{tabular}{|c|l|l|l|l|l|l|}
\hline In / Efficiency & Productivity & Performance & Self-evaluation & Surveys & Social media & Legitimacy \\
\hline $\begin{array}{c}\text { Within public } \\
\text { organization }\end{array}$ & & & & & & \\
\hline $\begin{array}{c}\text { Between } \\
\text { public } \\
\text { organizations }\end{array}$ & & & & & & \\
\hline $\begin{array}{c}\text { Public-private } \\
\text { partnerships }\end{array}$ & & & & & & \\
\hline Co-creation & & & & & & \\
\hline Private sector & & & & & & \\
\hline Through & & & & & \\
\hline
\end{tabular}

We can use this matrix to analytically map and locate existing attempts to measure public sector innovations.

First, however, based on our discussions above, we can derive a set of soft hypotheses (or expectations) from previous literature strands:

H1. Because of the influence of private sector innovation measurement literature,

H1a. efficiency and productivity are key drivers of why and how indicators for public sector innovations are created and used;

H1b. indicators mostly capture incremental changes rather than discontinuous change.

H2. As there are large gaps in public sector innovation literature on trust, legitimacy and similar issues,

H2a. these play almost no role in why and how indicators are created,

$\mathrm{H} 2 \mathrm{~b}$. but they do play some role in how they are used. 
H3. Given the widespread use of performance measurement systems in the public sector, we expect attempts at connecting these with innovation indicators.

H4. As legitimacy, trust and similar issues are difficult to measure, $\mathrm{H} 4 \mathrm{a}$. they are not captured at all by indicators and

H4b. direct feedback systems (social media) are not used.

H5. Public sector indicators capture either innovations within public organizations or through the public sector on businesses, but not both.

H6. Public sector innovation indicators capture public sector reactions to technological change and not public sector initiatives to drive technological change.

\section{Description of attempts and projects}

Quantitative large-scale studies aimed at measuring innovation have previously mostly targeted innovation in the private sector (e.g. Community Innovation Survey). Although there have been previous attempts at measuring public sector innovativeness (e.g. Roessner 1977), systemic approaches to public sector innovation surveys started to appear only during the recent decade. Arundel and Huber (2013) have conducted a literature search to identify 18 studies aimed at evaluating innovation in the public sector using 15 large-scale data sets. These studies focused on developed economies and also excluded service providers for health and education. Most of the studies did not cover all five categories of the public sector, mostly focusing on public administration. We have identified 5 such experiments that resulted in actual indicators developed and used at least once (these are summarized in Table 4):

- MEPIN (Measuring Public Innovation in the Nordic Countries). MEPIN project aimed at devising a conceptual framework and a survey questionnaire. The conceptual framework is built upon the insights from the Community Innovation Survey (CIS) that is intended for measuring innovation in the private sector, adjusted to suit the needs of the public sector, as well as on the existing work on public sector innovation. The preliminary conceptual framework was piloted in all five Nordic countries.

- European Public Sector Innovation Scoreboard (EPSIS). As part of a preliminary work in developing public sector innovation indicators, an Innobarometer survey was conducted in 2010, which consisted of 24 questions. The survey involved 500 public organizations coming from across public administration, higher education, local authorities and hospitals from 
all 27 member states. EPSIS was developed along the lines of the Innovation Union Scoreboard that targets innovation in business enterprise, distinguishing between three factors - enablers, activities and outcomes. However, in contrast to other studies mentioned here, EPSIS also includes measurements of the impact of public sector innovation on the performance of businesses.

- Australian Public Sector Innovation Indicators Project (APSII). The Australian Public Sector Innovation Indicators Project is the latest among the efforts around the world in measuring innovation in the public sector; and it incorporates all the lessons learned from earlier efforts of other countries discussed here. In contrast to the methodology applied in the European surveys (mirroring the CIS methodology), the APSII project proposed for a pilot a methodology based on a survey conducted in two modules - an agency and an employee survey. A conceptual framework used in the APSII project for measuring innovation in the public sector incorporates five main themes: inputs to innovation, innovation processes, outputs of innovation, outcomes of innovation, and environmental conditions that affect innovation in the public sector.

- United Kingdom (NESTA). In 2008-2009 the National Endowment for Science Technology and Arts (NESTA) commissioned six exploratory studies on public sector innovation with an aim to develop a new Innovation Index. The London School of Economics Public Policy Group (LSEPPG) developed its public sector innovation index on the basis of a survey of studies performed previously, thus taking into account the possible shortcomings and benefits of the previous efforts.

- Korean Government Innovation Index. The Government Innovation Index (GII) is an online innovation measurement tool devised by the Headquarters for Government Innovation under the Ministry of Government Administration and Home Affairs of Korea in 2005. The GII is one of the early efforts aimed at measuring innovation in the public sector, thus providing insights for the subsequent innovation indices developed elsewhere. The GII is designed to measure innovation in government agencies, focusing on a set of innovation management components, including innovation leadership; vision and strategy; personnel capacity; implementation of innovation; improvement of performance; and barriers to innovation. The data-collection process required three randomly selected representatives of respondent agencies to fill in the online questionnaire. 


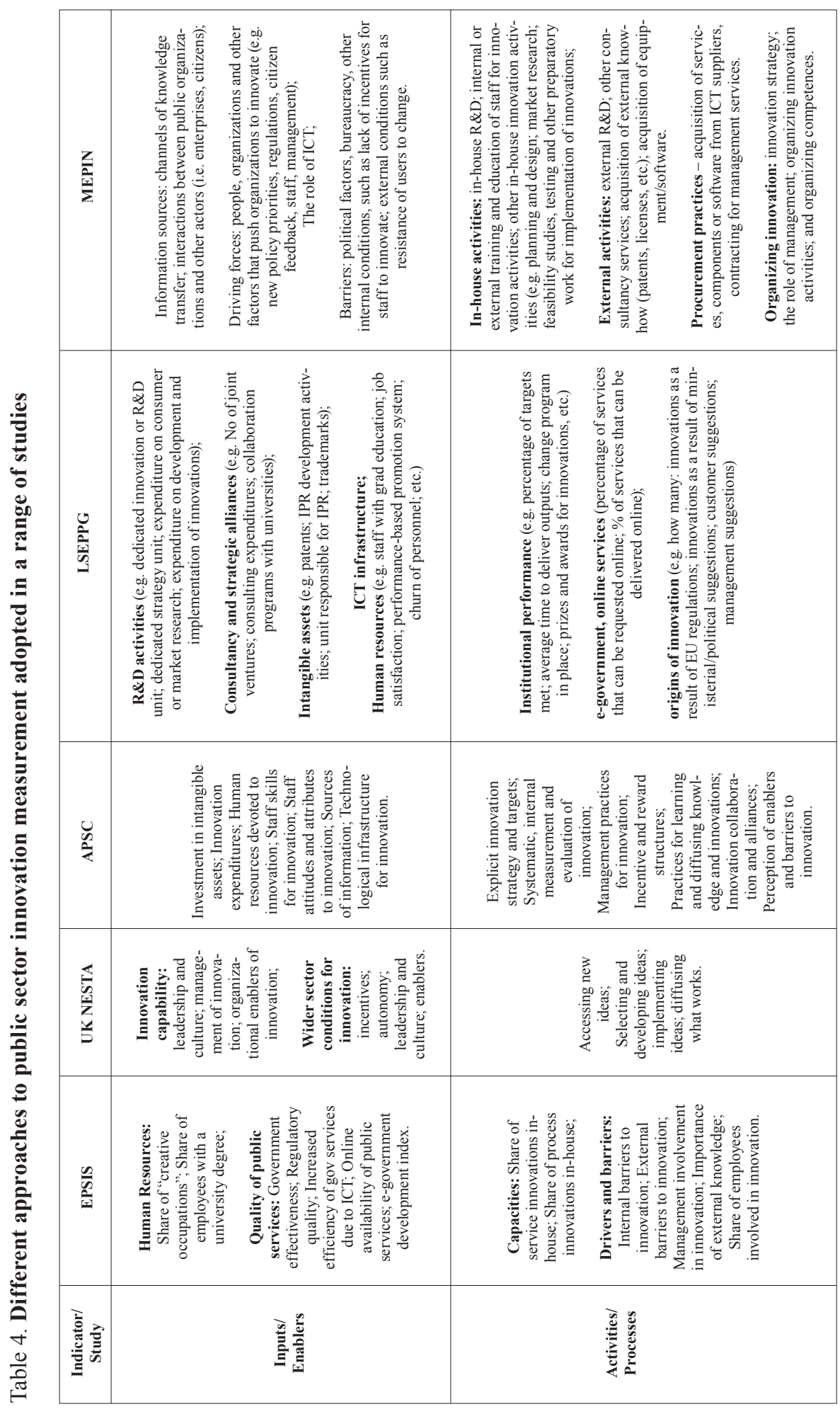




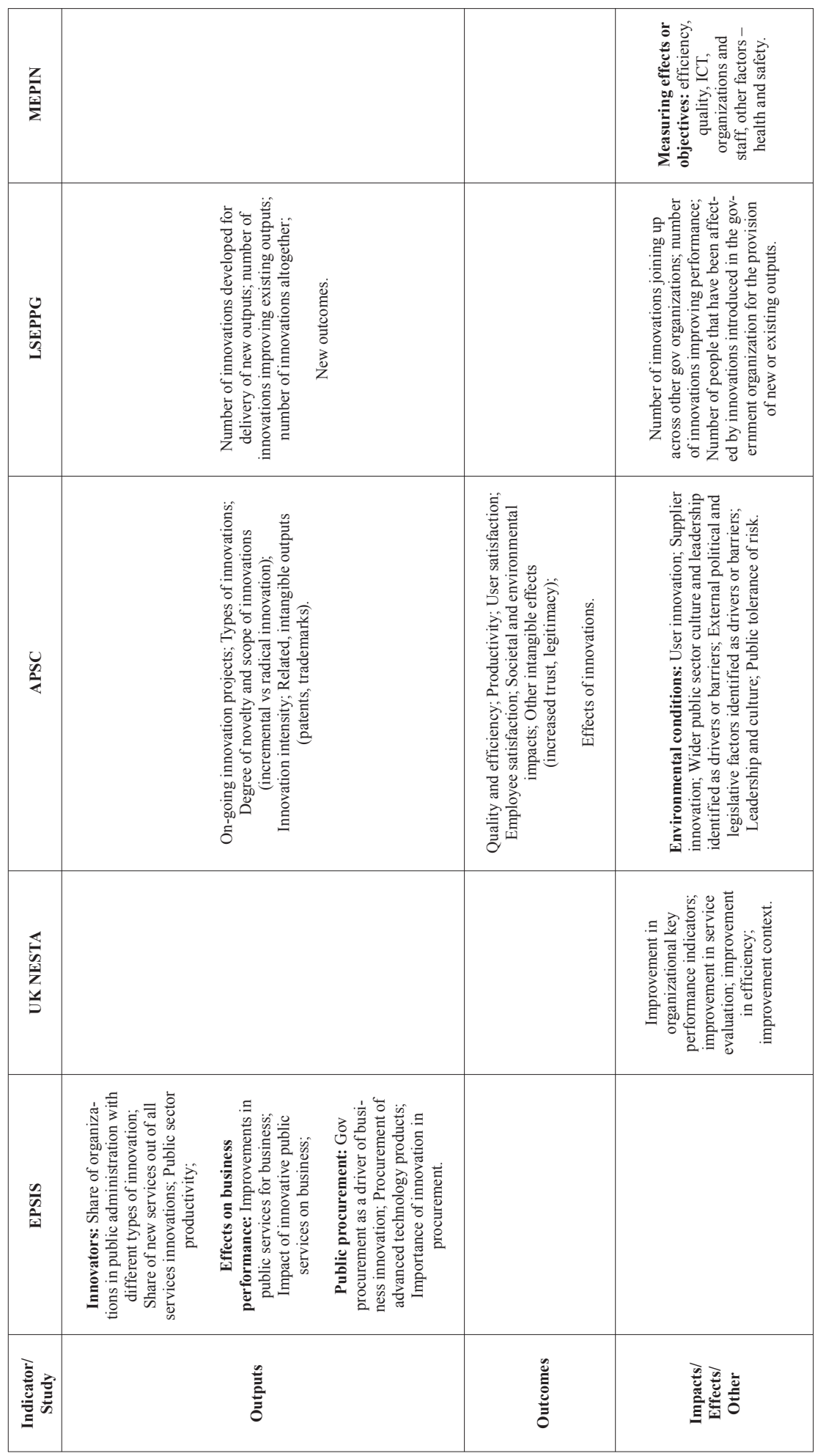




\section{Discussion}

We interviewed members from all five projects. ${ }^{7}$ We can bring out the following key strands of ideas emerging from interviews.

1. Motivations behind creating indicators. In most cases some form of political demand played an important role: as public sector innovations are an emerging issue for many governments, there is also a need to understand its impact better. Also supranational organizations such as the OECD and the EU play a crucial role in initiating, funding and facilitating such attempts. In all cases, organizations taking up the task of creating public sector innovation indicators had significant prior experience with measuring business innovations. However, the overarching idea behind creating new indicators for public sector innovations is strongly associated with justifying and legitimizing public sector activities.

1. Within the wider context of political demand, the current attempts to measure public sector innovation tend to also reflect individual preferences of sponsoring organizations. For example, EPSIS was designed in cooperation with various EC directorates and thus ended up measuring both innovation in the public sector and innovation through the public sector, whereas other attempts focused more on innovation within the public sector. The nature of political demand also had other important consequences on how the measurement efforts evolved. The demand in general has been short term oriented leading to the application of existing, but partially questionable private sector innovation methodologies. The ability to compare private and public sector innovation performance was one of the driving forces behind the application of the Oslo manual to the public sector context. In effect, the goal was to show that the public sector was as or at least comparably innovative. At the same time the political demand has been rather inconsistent, as in most cases it is not known if and how the measurement attempts will be prolonged.

2. Theoretical discussions and ideas behind indicators. In all cases key people involved with developing indicators were economists by background and readily admitted that business innovations were an important theoretical vantage point. However, all also admitted that the public sector has unique logics that are often difficult to separate from each other and consequently also to measure. Significantly, all projects realized only after the empirical exercises that they would have needed substantial input from public administration and governance scholarship. In addition to the need to add public sector specific logics, important difficulties were discovered in applying the existing private sector innovation measurement methodologies into the realm of the public sector. Issues like innovation output, significance of innovation and innovation failures that occupy a central place in private sec-

7 A list of interviews is in Appendix 1. The interview structure and questions are in Appendix 2. 
tor innovation measurement methodologies were almost impossible to measure in the context of the public sector. One of the lessons was that innovation perception is different (more problematic to discern between process and product innovation or to explain what is and what is not innovation) in the public sector and thus indeed assumes a revised theoretical framework for indicators and the definition of innovation itself for the public sector. At the same time, all projects seem to have been in discussion with each other and trying to learn from each other's successes and failures.

3. Relevance of productivity measurement. While productivity in the public sector was deemed an important driver of attempts to measure public sector performance, most experts argued that it is much too difficult to measure in the public sector, and thus their indicators do not reflect this or do so only indirectly by studying favorable conditions and inputs assumed to be capable of leading to higher productivity. Outcome measurement as a whole was very weak in all the measurement exercises.

4. Relevance of performance measurement. Performance measurement practices have played almost no role at all in developing public sector innovation indicators. At the same time performance measurement has been one of the most studied issues in recent public management debates and could provide ample ideas for linking performance measurement with innovation. This seems to be strongly related to missing public administration and management competencies in all projects.

5. Relevance of legitimacy, trust. Legitimacy and trust played no role at all in developing indicators. In a rare occasion it was seen as an important input to innovation, but it was not included in the measurement effort. As put by one of the respondents: "Trust is important, but we don't capture it in the measurement." Again, we can guess that is has to do with the fact that it is methodologically difficult to capture these issues and that experts with such skills were not involved.

6. Who uses indicators and how. Predicted use of indicators varies quite significantly from in-house management tools to country-to-country comparison and benchmarking. Also, as indicated above, the ability to compare private and public sector innovation performance was one of the motivations behind launching these attempts. The variety of use of the indicators reflects both the mixed motivations of individual sponsors of the measurement attempts and the limited validity and reliability of the results. However, it is important to note here that all the interviewed stakeholders were very aware of the limitations of the measurement attempts, which is why we can also see a rather different mix of actual use of the measurement results.

7. Future and evaluations of indicators. No projects have been formally evaluated; it is also not certain that any of the projects will be repeated in the future (EPSIS seems to be most certain to be repeated) or developed into a working tool for other organizations (OECD work on updating the Oslo manual will utilize some of the work done in MEPIN and EPSIS). This seems to stem from difficulties involved both on the technical side (availability, comparability of data) but also practicality (in most cases the results 
do not tell managers, politicians or citizens much, and it is expensive to gather new forms of indicators). Still, all the stakeholders - and in spite of the existing limitations - are positive regarding the need to continue with the measurement attempts and develop the indicators further. There are, however, different ideas around how to best proceed with the public sector innovation measurement attempts. By and large, these ideas fall into two groups: a) more sophisticated surveys that would better address the existing limitations, and b) more focused and narrower studies on specific public sectors and phases of innovation (e.g. adoption/diffusion).

We can also now look at our hypothesis again.

H1. Because of the influence of private sector innovation measurement literature,

H1a. efficiency and productivity are key drivers of why and how indicators for public sector innovations are created and used:

This is only partially the case because private sector measurement practices play an important role as far as the technical expertise of developers is concerned, at the same time the developers were acutely aware that private sector instruments and indicators cannot be used in the public sector. Also the ideas of efficiency and productivity play an important role as guiding ideas how to measure public sector performance (they were used in the conceptualization process), but at the same time due to data and other technical difficulties, these ideas are not strongly reflected in actual indicators.

H1b. indicators mostly capture incremental changes rather than discontinuous change:

As all indicators have strong survey elements, this seems to be the case since incremental changes are easy to report while discontinuous change is technically more difficult to define and hence also to report. In most cases the level of change - incremental or transformative - is not captured at all or only indirectly (by proxies: e.g., deployed person-months etc.) in the measurement effort. However, what was also indicated by the interviewees is that in most cases public sector innovation is perceived as something leading to positive impacts. Public servants find it very difficult to relate negative changes with innovation, meaning that many important incremental changes stay out of the public sector innovation measurement focus.

H2. As there are large gaps in public sector innovation literature on trust, legitimacy and similar issues,

H2a. these play almost no role in why and how indicators are created,

This was indeed so; also because no experts with public administration and management skills were involved in any of the projects. 
H2b. but they do play some role in how they are used.

All people interviewed admitted that this indeed would be an important issue for future indicators. At the same time they brought out problems of conceptualizing and measuring legitimacy.

H3. Given the widespread use of performance measurement systems in the public sector, we expect attempts at connecting these with innovation indicators.

This was not at all the case, also because no experts with public administration and management skills were involved in any of the projects. At the same time, it can be argued that most projects in fact wanted to measure and capture public sector performance, which is why certain organizations perform better than others. This was, however, often clothed in different, private sector innovation language (e.g. in terms of barriers, drivers, funding, and other indicators). On the basis of this we can argue that approaches for measuring innovation in the private sector, including service innovation, are not instantly applicable to public sector innovation and need to be adjusted.

H4. As legitimacy, trust and similar issues are difficult to measure,

H4a. it is not captured at all by indicators.

This was indeed the case as admitted by all respondents.

H4b. and direct feedback systems (social media) are not used.

This was indeed confirmed, at the time when research was conducted there seemed to be no attempts under way to use social media or relevant feedback mechanisms for public sector innovation measurements.

H5. Public sector indicators capture either innovations within public organizations or through the public sector on businesses, but not both.

The different indicators indeed tried to capture either one or the other. There were no attempts, for instance, to capture various PPP or co-creation practices, although PPP and outsourcing were studied as indicators of innovation through public sector.

H6. Public sector innovation indicators capture public sector reactions to technological change and not public sector initiatives to drive technological change.

Indeed, there were no indicators capturing the latter, the only exception is the MEPIN project.

Finally, we can plot all existing exercises of indicators on our theoretical matrix. 
Table 5. Existing exercises at the measurement of public sector innovation evaluation matrix.

\begin{tabular}{|c|l|l|l|l|l|l|}
\hline In / Efficiency & Productivity & Performance & Self-evaluation & Surveys & Social media & Legitimacy \\
\hline $\begin{array}{c}\text { Within public } \\
\text { organization }\end{array}$ & $\begin{array}{c}\text { APSI } \\
\text { NESTA }\end{array}$ & APSII & & & \\
\hline $\begin{array}{c}\text { Between } \\
\text { public } \\
\text { organizations }\end{array}$ & & & MEPIN & & & \\
\hline PPP & & & & & & \\
\hline Co-creation & EPSIS & EPSIS & & & & \\
\hline Private sector & & & & & & \\
\hline Through & & & & & \\
\hline
\end{tabular}

While none of the project fit into only one definite box in our matrix, it is also clear that the existing projects to develop public sector innovation indicators are rather strongly biased towards measuring only specific types of activities within or through the public sector and use a relatively limited set of tools for this. The current approaches to measuring innovation in the public sector are to a large extent based on experiences in measuring innovation in the private sector and have been developed by experts without specific knowledge of the public sector. Therefore, these attempts, focusing largely on how innovations affect efficiency and the performance of public organizations, disregard the aspects of trust and legitimacy, which are both key indicators of the performance of public sector organizations. These approaches also treat public sector organizations as consumers of technology and disregard the capacity of public sector organizations to drive technological change. In part this also explains the focus on incremental change, while radical transformations do not receive the attention those deserve. This can also be partly explained by the fact that public sector innovation is largely perceived through the prism of service innovation literature, which itself focuses largely on incremental organizational change.

Based on our theoretical matrix, we can deduct the most important gaps in the current public sector innovation measurement practices:

1. Public administration attempts to evaluate and analyze public sector performance should be utilized when developing public sector innovation measurement tools.

2. Experimental designs utilizing social media as an instant feedback loop for public sector activities should offer new and interesting avenues to link legitimacy and trust issues to public sector innovation measurements.

3. Inter-organizational and citizen-public sector partnership practices should be considered as a central dimension in enabling or constraining experimentation and thus be carefully measured in order to understand innovation in the public sector. 
4. The target group for such measurement exercises should be more clearly outlined: citizens (measurement used as a communication tool), politicians (as a feedback tool) or civil servants (as a learning tool).

In sum, as an alternative way of conceptualizing the measurement of public sector innovations, we propose to use evaluation frameworks, as we used above. In our view such matrixes can be turned into evaluation tools both within public sector organization and used as feedback tools, and also for external evaluations of various public sector innovations. 


\section{REFERENCES}

Allman, K., Edler, J., Georghiou, L., Jones, B., Miles, I., Omidvar, O., Ramlogan, R. and J. Rigby. 2011. Measuring Wider Framework Conditions for successful innovation. A system's review of $U K$ and international innovation data. London: NESTA

Andersen, E.S. 2009. Schumpeter's Evolutionary Economics: A Theoretical, Historical and Statistical Analysis of the Engine of Capitalism. London: Anthem Press.

Andrews, R. and T. Entwistle. 2013. "Four Faces of Public Service Efficiency: What, how, when and for whom to Produce." Public Manag. Rev. 15, 246264.

Arnaboldi, M. and G. Azzone. 2010. "Constructing Performance Measurement in the Public Sector." Crit. Perspect. Account 21, 266-282.

Arundel, A. and D. Huber. 2013. From too Little to too Much Innovation? Issues in Measuring Innovation in the Public Sector. Urbino: University of Urbino.

Banerjee, A.V. and E. Duflo. 2009. The experimental approach to development economics. Annu. Rev. Econ., 1(1), 151-178.

Banerjee, A., Duflo, E., Glennerster, R. and C. Kinnan. 2015. The miracle of microfinance? Evidence from a randomized evaluation. American Economic Journal: Applied Economics, 7(1), 22-53.

Becker, S.W. and T.L. Whisler. 1967. "The Innovative Organization: A Selective View of Current Theory and Research." J. Bus. 40(4), 462-469.

Bloch, C. 2011. Measuring Public Innovation in the Nordic Countries: Copenhagen Manual, Measuring Public Innovation in Nordic Countries. Aarhus: The Danish Centre for Studies in Research and Research Policy (CFA).

Brax, S.A. 2007. "Palvelut ja tuottavuus." Teknologiakatsaus 204/2007. Helsinki: TEKES.

Bugge, M.M., P.S. Mortensen and C. Bloch. 2011. Measuring Public Innovation in Nordic Countries. Report on the Nordic Pilot studies: Analyses of methodology and results (No. 40/2011). Oslo: NIFU/Innovasjon Norge.

De Bruijn, H. 2002. "Performance Measurement in the Public Sector: Strategies to Cope with the Risks of Performance Measurement." Int. J. Public Sect. Manag. 15, 578-594.

DIISR. 2011. Measuring Innovation in the Public Sector: A Literature Review. Canberra: Department of Innovation, Industry, Science and Research, Australian Government.

Djellal, F., F. Gallouj and I. Miles. 2013. "Two Decades of Research on Innovation in Services: Which Place for Public Services?" Structural Change and Economic Dynamics 27, 98-117.

Drechsler, W. 2005. "The Rise and Demise of the New Public Management." PostAutistic Econ. Rev.

Drechsler, W. 2019. "Kings and Indicators: Options for Governing without Numbers.” In M.J. Prutsch (ed.). 'Working Numbers': Science and Contemporary Politics. Basingstoke: Palgrave Macmillan, in press. 
Dunleavy, P. and L. Carrera. 2013. Growing the Productivity of Government Services. Cheltenham: Edward Elgar Publishing.

EC. 2013. European Public Sector Innovation Scoreboard: A Pilot Exercise. Brussels: European Commission, DG Enterprise and Industry.

Etzioni, A. 1964. Modern Organization. Englewood Cliffs: Prentice Hall

EU Expert Group on Public Sector Innovation. 2013. Powering European Public Sector Innovation: Towards A New Architecture. Brussels: DG Research and Innovation, EC.

Eun Kim, S., J. Wook Lee and B. Seob Kim. 2007. The Quality of Management and Government Innovation: An Empirical Study. Tucson, AZ: University of Arizona.

Fuglsang, L. 2010. "Bricolage and Invisible Innovation in Public Service Innovation.” J. Innov. Econ. 1, 67-87.

Gallouj, F. and A. Zanfei. 2013. "Innovation in Public Services: Filling a Gap in the Literature." Struct. Change Econ. Dyn. 27, 89-97. doi:10.1016/j.strueco.2013.09.002

Hartley, J. 2005. "Innovation in Governance and Public Services: Past and Present." Public Money Manag. 25, 27-34.

Hasan, M. and R. Kerr. 2003. "The Relationship between Total Quality Management Practices and Organisational Performance in Service Organisations." TQM Mag. 15, 286-291.

Kattel, R., A. Cepilovs, W. Drechsler, T. Kalvet, V. Lember and P. Tõnurist. 2013. Can we Measure Public Sector Innovation? A Literature Review Research Report No.6. LIPSE Learning from Innovation in Public Sector Environments. Available online (last accessed 03 October 2018): http://www.lipse.org/upload/publications/Research\%20Report_LIPSE\%20WP6_FINAL_20151130.pdf

Kattel, R., M. Mazzucato, J. Ryan-Collins and S. Sharpe. 2018. The economics of change: Policy and appraisal for missions, market shaping and public purpose IIPP Policy Report 2018-06. Available online (last accessed 03 October 2018): https://www.ucl.ac.uk/bartlett/public-purpose/sites/public-purpose/files/iipp-wp-2018-06.pdf

Kuhlmann, S. 2010. "Performance Measurement in European Local Governments: A Comparative Analysis of Reform Experiences in Great Britain, France, Sweden and Germany." Int. Rev. Adm. Sci. 76, 331-345.

Lane, J.E. 2000. New Public Management. London: Routledge

Lonti, Z. and R. Gregory. 2007. "Accountability or Countability? Performance Measurement in the New Zealand Public Service, 1992-2002." Aust. J. Public Adm. 66, 468-484.

LSEPPG. 2008. "Innovation in Government Organizations, Public Sector Agencies and Public Service NGOs." Draft Working Paper. London: NESTA/LSE Public Policy Group.

Lynn, L. 1997. "Innovation and the Public Interest: Insights from the Private Sector." In A.A. Altshuler and R.D. Behn (eds). Innovation in American Government: Challenges, Opportunities, and Dilemmas. Washington, DC: The Brookings Institution, 83-103.

Miller, D. 2003. “The Virtual Moment.” J. R. Anthropol. Inst. 9, 57-75. 
Mohr, L.B. 1969. "Determinants of Innovation in Organizations." Am. Polit. Sci. Rev. 63(1), 111-126.

Moore, M., 1994. "Public value as the focus of strategy." Australian Journal of Public Administration, 53(3), 296-303.

Moore, M. and J. Hartley. 2008. "Innovations in Governance." Public Manag. Rev. 10, 3-20.

Noordegraaf, M. and T. Abma. 2003. "Management by Measurement? Public Management Practices amidst Ambiguity." Public Adm. 81, 853-871.

O’Flynn, J. 2007. "From New Public Management to Public Value: Paradigmatic Change and Managerial Implications." Aust. J. Public Adm. 66, 353-366.

Osborne, D. and T. Gaebler. 1992. Reinventing Government. Lexington, MA: Addison-Wesley.

Osborne, S.P. and K. Brown. 2005. Managing Change and Innovation in Public Service Organizations. New York: Routledge.

Osborne, S.P. and K. Brown. 2013. "Introduction: Innovation in Public Services." In S.P. Osborne and K. Brown (eds). Handbook of Innovation in Public Services. Cheltenham: Elgar, 1-11.

Packard, T. 2010. "Staff Perceptions of Variables Affecting Performance in Human Service Organizations." Nonprofit Volunt. Sect. Q. 39(6), 971-990.

Pidd, M. 2008. "A Critical Assessment of Performance Measurement for Policy Making." In J. Hartley, C. Donaldson, C. Skelcher and M. Wallace (eds). Managing to Improve Public Services. Cambridge: Cambridge University Press, 65-87.

Pollitt, C. 2011. "Innovation in the Public Sector: An Innovatory Overview." In V.J.J.M. Bekkers, J. Edelenbos and B. Steijn (eds). Innovation in the Public Sector: Linking Capacity and Leadership. Basingstoke: Palgrave Macmillan, 35-43.

Pollitt, C. and G. Bouckaert. 2011. Public Management Reform: A Comparative Analysis-New Public Management, Governance, and the Neo-Weberian State. Oxford: Oxford University Press.

Porter, M.E. 2010. "What is Value in Health Care?” N. Engl. J. Med. 363, 2477-2481.

Ridgway, V.F. 1956. "Dysfunctional Consequences of Performance Measurements." Adm. Sci. Q. 1(2), 240-247.

Rittel, H.W. and M.M. Webber. 1973. "Dilemmas in a General Theory of Planning." Policy Sci. 4, 155-169.

Roessner, J.D. 1977. "Incentives to Innovate in Public and Private Organizations." Adm. Soc. 9, 341-365.

Rutgers, M.R. and H. van der Meer. 2010. "The Origins and Restriction of Efficiency in Public Administration Regaining Efficiency as the Core Value of Public Administration." Adm. Soc. 42, 755-779.

Sahay, B. 2005. "Multi-Factor Productivity Measurement Model for Service Organisation." Int. J. Product. Perform. Manag. 54, 7-22.

Schumpeter, J.A. 1912. Theorie der wirtschaftlichen Entwicklung. Berlin: Duncker\&Humblot.

Schumpeter, J.A. 1939. Business Cycles: A Theoretical, Historical, and Statistical Analysis of the Capitalist Process. New York: McGraw-Hill. 
Sheldon, T. and A. Oakley. 2002. "Why we need Randomized Controlled Trials." In L.Duley and B.Farrell, (eds.). Clinical Trials. London: BMJ Publishing, 13-24.

Sillanpää, V. 2013. "Measuring the Impacts of Welfare Service Innovations.” Int. J. Product. Perform. Manag. 62, 474-489.

Smith, P. 1995. "On the Unintended Consequences of Publishing Performance Data in the Public Sector." Int. J. Public Adm. 18, 277-310.

Tangen, S. 2005. "Demystifying Productivity and Performance." Int. J. Product. Perform. Manag. 54, 34-46.

Thompson, V.A. 1965. "Bureaucracy and Innovation." Adm. Sci. Q. 10(1), 1-20.

Tocqueville, A.D. 1876. Democracy in America. Bonston: John Allyn.

Torgerson, D.J. and C. Torgerson. 2008. Designing Randomised Trials in Health, Education and the Social Sciences: An Introduction. Basingstoke: Palgrave Macmillan.

Van Thiel, S. and F.L. Leeuw. 2002. "The Performance Paradox in the Public Sector." Public Perform. Manag. Rev. 25, 267-281.

Verhoest, K., B. Verschuere, G. Bouckaert and B.G. Peters. 2006. "Innovative Public Sector Organizations.” In C. Campbell (ed.). Comparative Trends in Public Management: Smart Practices Toward Blending Policy and Administration. Ottawa: Canada School of Public Service, 106-118.

Voorberg, W.H., V.J. Bekkers and L.G. Tummers. 2015. "A Systematic Review of Co-Creation and Co-Production: Embarking on the Social Innovation Journey." Public Management Review 17(9), 1333-1357.

Weber, M. 2002. Wirtschaft und Gesellschaft: Grundriß der Verstehenden Soziologie. $5 \mathrm{t}^{\mathrm{h}}$ edn. Tübingen: Mohr Siebeck.

Wilson, J.Q. 1989. Bureaucracy: What Government Agencies do and why they do it. New York: Basic Books.

\section{Appendix 1. List of Interviews}

1. Hugo Hollanders, Senior Researcher at Maastricht University, Member of the EC's 2010 High-Level Panel on the Measurement of Innovation, EPSIS project team, 7 July 2014 (skype).

2. Carter Bloch, Aarhus University, Department of Political Science and Government, Danish Centre for Studies in Research and Research Policy, Associate Professor, MEPIN leader and coordinator, 8 July 2014 (skype).

3. Anthony Arundel, Professor of Innovation at the AIRC, University of Tasmania and Professional Fellow at UNU-MERIT, APSII team, 10 July 2014 (skype).

4. Dorothea Huber, Graduate Research Candidate at the AIRC, University of Tasmania, APSII team, 10 July 2014 (skype).

5. Thorsteinn Gunnarsson, RANNIS, Icelandic Centre for Research, Head of Division of Evaluation and Analysis, representative from Iceland within MEPIN, 11 July 2014 (skype).

6. Viola Peter, Senior Consultant at Technopolis Group Brussels Office, EPSIS team, 23 July 2014 (skype). 
7. Ari Leppälahti. Statistics Finland, Business Statistics, Senior Adviser, representative from Finland within MEPIN, 27 July 2014 (e-mail).

8. Nick Yazidjoglou, Government Administration, Department of Innovation, Industry, Science and Research, APSII coordinator, 28 July 2014 (skype).

9. Stian Westlake, Nesta, Executive Director of Policy and Research, Nesta, Innovation in public sector organizations project, 5 August 2014 (telephone).

10. Markus Bugge, NIFU - Nordic Institute for Studies in Innovation, Research and Education, senior researcher, coordinator of MEPIN in Norway, 8 August 2014 (skype).

11. Tomasz Jerzyniak, Policy Officer, European Commission, DG Enterprise and Industry, EPSIS coordinator, 20 August 2014 (telephone).

12. Per Melchior Koch, Innovation Norway, Special Advisor, member of the reference group for the MEPIN project for Norway, 22 August 2014, (telephone).

13. Svein Olav Nas, Research Council Norway (currently), at the time of MEPIN with NIFU-STEP, 22 August 2014 (skype).

\section{Appendix 2. Interview structure and questions}

\section{A. Institutional and Organizational background}

1. How widespread are attempts in your country to

- start PSI oriented reforms/activities?

- measure (or evaluate) such reforms/activities?

2. Why was your organization involved in PSI indicators/project? Does your organization have previous background in such activities?

3. How many people from your organization were involved?

4. Did your organization coordinate activities with other organizations?

- If yes, why?

5. Who funded the effort (if you can reveal it)?

- Is it an on-going effort or a one-off project?

6. Who are the clients for your indicators, in which policy cycle phase do you think they should use it?

\section{B. Theoretical and conceptual background}

1. Before devising specific indicators, how extensive were the theoretical and conceptual discussions you had?

- How long did discussions last?

- Were they about what can be measured in the public sector? 
- Were they about what is PSI?

- Were they about learning from other similar attempts?

- What were your main lessons from such discussions?

2. Before devising specific indicators, how extensive were the discussions about quantitative vs qualitative indicators?

3. How would you characterize the main theoretical assumptions behind your PSI indicators project?

- How important are the ideas of efficiency, productivity?

- Do you differentiate between different types of innovations?

- How important are ideas and practices from performance management/measurement?

- How important are ideas and practices from quality management/measurement?

- How important are the ideas of legitimacy, trust, etc?

\section{Actual attempts at measurements}

1. How does your indicator or set of indicators work?

- What are the main sources of data?

- How do you deal with the problem of comparability?

- Does our organization do it for other organizations?

- Do organizations do it themselves?

- Is there a statistical organization filling in data?

2. How many times has your indicator been used/tested?

- What type of organizations have been using it (if applicable)?

\section{Evaluation and future plans}

1. How would you evaluate your PSI indicators?

- Has there been a formal evaluation of some type?

- Have other organizations been involved in evaluating the indicators?

- Do they "work" in your opinion, deliver what you hoped they would?

If yes, in what sense?

If no, why not?

2. Do you plan to use the indicators in the future?

- Will the indicators be modified?

- Will you attempt to develop new indicators? 
RAINER KATTEL is professor of innovation and public governance at the Institute for Innovation and Public Purpose, University College London, and research professor at Ragnar Nurkse Department of Innovation and Governance, Tallinn University of Technology, Estonia. He has studied at the University of Tartu, Estonia, and University of Marburg, Germany, in philosophy, political philosophy, classics and public administration. He has published extensively on innovation policy, its governance and specific management issues. Email: r.kattel@ucl.ac.uk

Aleksandrs CePIlovs is project manager at the Ragnar Nurkse Department of Innovation and Governance, Tallinn University of Technology, Estonia. He has studied economics and technology governance and has received his $\mathrm{PhD}$ from the Ragnar Nurkse Department. His research interests are in innovation policy, public sector innovation and policy transfer, with a specific focus on Central and Eastern Europe. Email: aleksandrs.cepilovs@ taltech.ee

Veiko Lember is Marie Curie Research Fellow at the KU Leuven Institute of Public Governance, Senior Research Fellow in Public Management and Policy at the Ragnar Nurkse Department of Innovation and Governance, Tallinn University of Technology, and a visiting researcher at LISIS, Université Paris-Est. He holds BA and MA from the University of Tartu and PhD from Tallinn University of Technology. His research interests are in public administration and innovation policy, and his recent works have covered issues such as public administration and technology, public sector innovation, public-private partnerships and co-production as well as innovation policy governance broadly. Email: veiko.lember@taltech.ee

PIRET TónuRIST currently works at the Directorate for Public Governance, OECD, as a lead in systems thinking and innovation measurement in Observatory of Public Sector Innovation (OPSI). She also holds a research fellowship at the Ragnar Nurkse Department of Innovation and Governance, Tallinn University of Technology. Piret does research in Organizational Studies, Public Sector Innovation, Technology and Environmental Politics and Public Policy. Previously she has worked as a consultant to the parliament, performance auditor and freelance consultant. Piret Tõnurist holds a PhD and MA from Tallinn University of Technology in technology governance and Master of Science from KU Leuven in policy evaluation. Email: piret.tonurist@taltech.ee 